\title{
Wound care challenges in children and adults with spina bifida: An open-cohort study
}

\author{
Katherine Ottolini ${ }^{\mathrm{a}}$, Amy B. Harris ${ }^{\mathrm{b}}$, June K. Amling ${ }^{\mathrm{b}}$, Ann M. Kennelly ${ }^{\mathrm{b}}$, Leslie A. Phillips ${ }^{\mathrm{b}}$ and \\ Laura L. Tosi ${ }^{\mathrm{a}, \mathrm{b}, *}$ \\ ${ }^{a}$ George Washington University School of Medicine, Washington, DC, USA \\ ${ }^{\mathrm{b}}$ Children's National Medical Center, Washington, DC, USA
}

Accepted for publication: 16 June 2012

\begin{abstract}
Skin breakdown is a frequent concern for individuals with spina bifida. We explored wound incidence in patients with spina bifida and how it varies across a person's life span and functional neurologic level. We examined the settings in which skin breakdown most commonly occurred, looking for evidence of chronic, non-healing wounds. We also sought to develop criteria to improve wound monitoring. We identified reported wound episodes in an open-cohort study over a 13-year period, examining the hospital and outpatient clinical records of spina bifida patients at Children's National Medical Center (CNMC). Current age, age at wound presentation, sex, weight, functional neurologic level, wound location, setting in which the wound was acquired, the development of a chronic wound, and presence of a shunt were recorded. Of the 376 patients in our clinical population, 123 (average age: 18.8 years, range: infancy-56 years) developed a total of 375 wounds; the majority of patients who developed one wound went on to develop one or more additional wounds, and 20 patients developed chronic wounds. Our data suggest that age bracket (adolescents), wheelchair use, and bare feet, as well as possibly obesity and reduced executive functioning, are key risk factors for wound development. These findings have led to a focused effort to increase wound education and prevention. In addition we report on our early experience using a wound care specialist to champion this initiative.
\end{abstract}

Keywords: Spina bifida, chronic wounds, skin breakdown, wound care, children

\section{Introduction}

The incidence of spina bifida births in the United States has been falling steadily for several decades [13], particularly since 1998 when the Food and Drug Administration required the addition of folic acid to all standardized enriched-grain products sold in the United States [1]. At the same time, improved care techniques such as shunting of hydrocephalus (developed circa 1950) [4,5] and early closure of the spina bifida defect [6], have led to markedly improved survival rates (over $90 \%$ in the first year of life in the U.S.) $[7,8]$. In addition, several authors have noted that

* Corresponding author: Laura L. Tosi, Division of Orthopedics and Sports Medicine, Children's National Medical Center, 111 Michigan Avenue, NW, Washington, DC 20010, USA. Tel.: +1 202476 4063; Fax: +1 202476 4613; E-mail: ltosi@ childrensnational.org. up to $75 \%$ of children born with spina bifida in the United States are now surviving into adulthood $[9,10]$. No broad epidemiologic studies on the prevalence of spina bifida in the adult community have yet been undertaken; however, anecdotal evidence suggests that while the number of spina bifida live births has declined significantly, the prevalence may be rising or, at the very least, stable. This news, though heartwarming, poses new challenges to the medical community generally, and to orthopedists specifically.

Historically, orthopedic care for spina bifida at Children's National Medical Center (CNMC) focused on procedures to improve ambulatory function or reduce scoliosis. The need for and number of these surgeries declined substantially over the past two decades as a result of the falling incidence of spina bifida and improvements in a number of therapies, particularly for the management of clubfeet. However, at the same time, we have noted a marked increase in the num- 


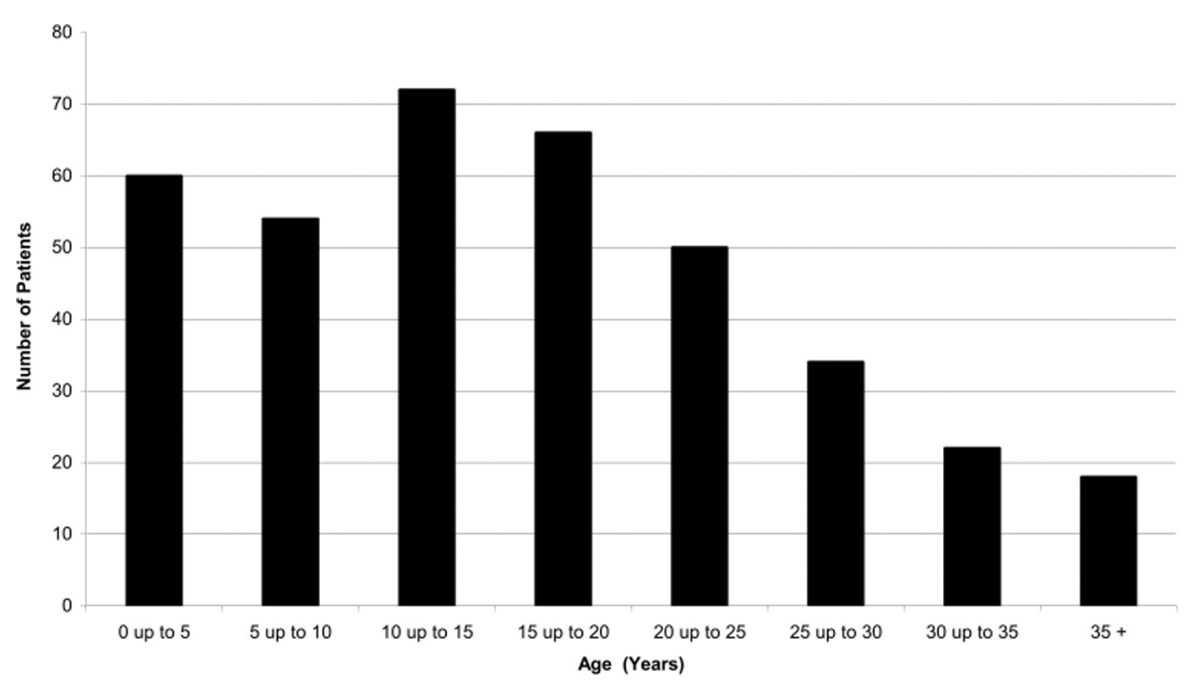

Fig. 1. Patients with spina bifida followed at Children's National Medical Center as of June 2009 ranged in age from infancy to 56 years.

ber of patients with wounds, some extremely difficult to eradicate. Depending on functional neurologic level, patients with spina bifida may have decreased or absent skin sensation in the trunk, buttocks, and lower extremities, leaving them vulnerable to wound formation [1118]. Wound care research to support individuals with spinal cord injury (SCI) and diabetes has led to many advances in wound care technology that can be applied to the care of patients with spina bifida $[19,20]$. One of the critical advances has been the recognition of the chronic, non-healing wound (defined as being stalled in a persistent hyper-inflammatory state) as a distinct biologic entity requiring specialized therapy [21-23]. At our institution, the number of patients with wounds, frequently with delayed healing, has become so great that dedicated time for their care has been set aside in the orthopedic schedule.

This paper was undertaken in an effort to better understand the increasing need for wound care in our spina bifida population. We had four goals: 1) to document the incidence of wounds to inform patients and parents about how wound risk varies across the lifespan and in relation to functional neurologic level; 2) to determine the setting in which wounds were most likely to occur; 3 ) to explore which wounds become chronic wounds; 4) to identify monitoring criteria and management approaches that might lead to improvements in wound prevention and care.

\section{Patients and methods}

We performed an open-cohort study, reviewing the hospital and outpatient clinical records of the 402 pa- tients actively followed (i.e., seen within the last two years) in the CNMC Multidisciplinary Spina Bifida Clinic from July 1996 through June 2009 to identify all reported episodes of wounds, including pressure ulcers, abrasions, and postsurgical wounds. Of these patients, 26 were excluded as a result of a diagnosis other than spina bifida (e.g., traumatic spinal cord injury or spinal cord tumor), leaving a total of 376 patients ranging in age from infancy to 56 years (Fig. 1). We defined spina bifida broadly and included patients with lipomeningocoele, sacral agenesis, and split cord malformation in our study.

In patients with a wound history, we recorded sex, weight, current age and age at the time of each wound, functional neurologic level as documented by the neurosurgical team, wound location, number of wounds, and the presence or absence of a shunt for the treatment of hydrocephalus. Wound locations were recorded as: (1) trunk (including axilla and abdomen, as well as over a gibbus); (2) buttock (including sacral and ischial wounds); (3) knee and thigh; (4) foot and ankle. During the review period of this study, height was only measured in ambulatory patients; arm span was not recorded. Thus, standard BMI measures could not be calculated for this analysis [24,25]. Based on the authors' long standing relationships with this patient cohort, however, we could assign the diagnosis of obesity based on the authors' consensus in patients with chronic wounds and buttock wounds. In addition, because wound management has only recently become a focus for our clinic, we used repeated clinic visits for the same wound and need for rehabilitation hospital admission for wound care as surrogates 


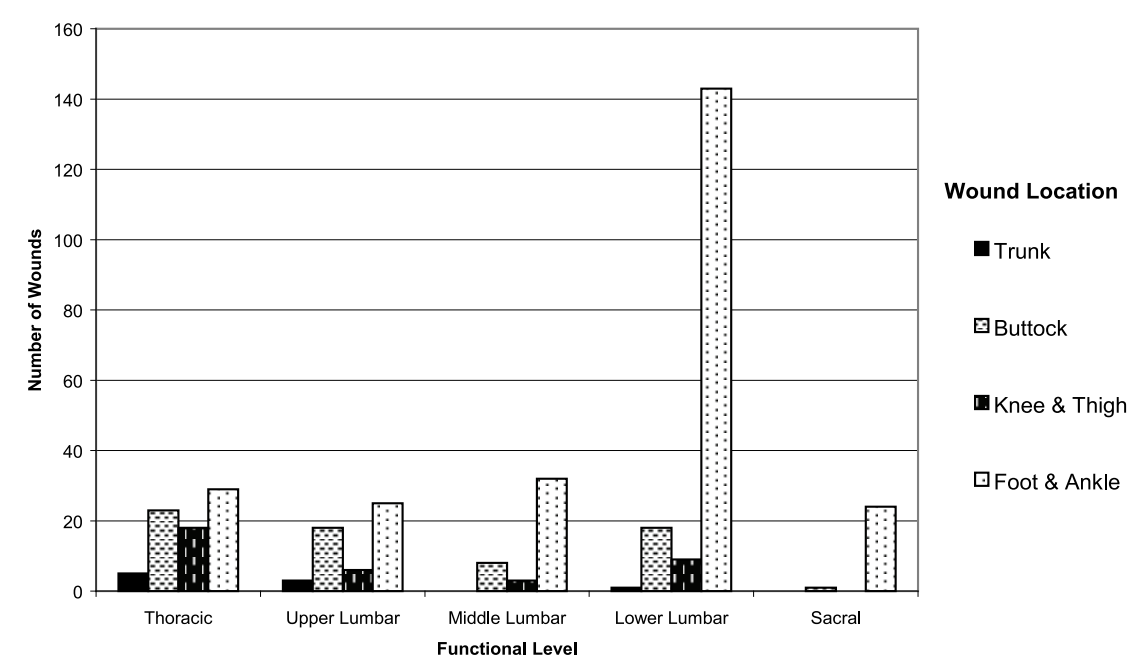

Fig. 2. The location of skin breakdown was influenced by the patient's functional neurologic level.

for identifying chronic wounds in some cases. The setting in which wounds developed was described as community-acquired, hospital-acquired, or postsurgical.

We performed descriptive statistical analysis only.

\section{Results}

\subsection{Wound incidence and risk factors}

\subsubsection{Patient demographics}

We identified 123 patients with spina bifida $(32.7 \%$ of our eligible spina bifida clinic population of 376 ; average age, $18.8 \pm 8.7$ years, versus 17.3 years for the overall spina bifida clinic population) who had a total of 375 skin wounds documented over the 13 years of observation included in this study. Female patients with wounds comprised $40.65 \%$ of this cohort (50/123), and overall females represented 51.06\% (192/376) of the entire spina bifida clinic population. Patients ranged in age from infancy to 56 years (Fig. 1). The average length of observation was $10.2 \pm$ 4.1 years. Wounds were most common in the teenage population and least frequent in children younger than 5 years of age and in adults between the ages of 3035 years. Only 4 of 18 patients ages 35 years and above developed wounds, but each of these 4 developed an average of 5 wounds.

\subsubsection{Functional neurologic level}

Patients who used wheelchairs as their primary source of mobility incurred a disproportionate share of the wounds. While 77 of $174(44 \%)$ wheelchair users incurred a wound, 228 of the 375 documented wounds $(61 \%)$ occurred in this group. Patients with thoraciclevel motor function had more breakdown about the trunk and buttocks and proportionately fewer episodes of foot/ankle and knee breakdown than did patients with lumbar or sacral functional levels (Fig. 2).

\subsubsection{Wound location}

Wounds to the foot and ankle were common in every age distribution except 30 to 35 -year-olds (Fig. 3). The foot and ankle were the most common wound sites, regardless of the patient's level of neurologic functioning. Most foot wounds were superficial abrasions and healed uneventfully. Heel ulcers were rare, and most wounds were on the forefoot. Infants and young children demonstrated a wider range of wound etiologies than older patients. Four children in our study group had serious burns and two developed cellulitis/osteomyelitis from chewing on their feet.

The second most frequent wound site was the buttocks, and these wounds occurred in patients of all functional neurologic levels. Buttock wounds occurred primarily in teens and adults, and the majority of these patients were not obese. Possible causes of buttock breakdown, such as problems with wheelchair cushions, failure to weight shift, failure to catheterize regularly, or urinary tract infections, were not typically documented in the patient records.

In young children, breakdown about the trunk was attributed to severe kyphosis and a prominent gibbus; in the few older children with trunk wounds, injury was attributed to a range of causes, including axillary hidradenitis. 


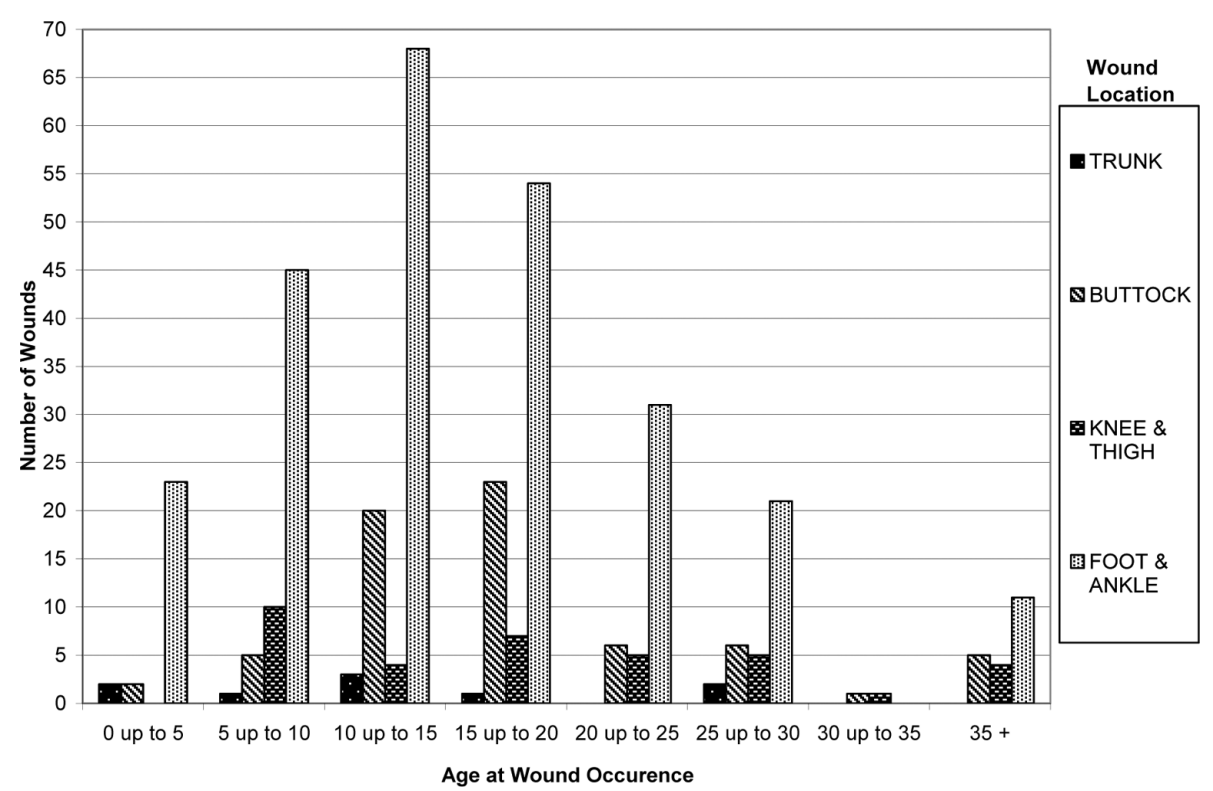

Fig. 3. Chart showing that wound locations changed over the patients' lifespans.

Wounds about the knee were uncommon and were typically attributed to crawling on insensate limbs or to pressure from knee pads used in long-leg braces.

\subsubsection{Number of wounds}

Fifty-three percent of patients who sustained a wound had two or more wound episodes (Fig. 4). In patients with a history of two or more wounds, 31 of 65 $(48 \%)$ had wounds in more than one location, typically the buttocks and feet.

\subsubsection{Shunt}

Eighty percent of patients with wounds had a shunt, which is consistent with the general spina bifida population.

\subsection{Wound setting: Community acquired}

Most wounds (260/275) were community acquired. Foot and ankle injuries occurred predominantly in patients with low-lumbar functional levels who were ambulators, consistent with the fact that such individuals are strong enough to be good walkers but have diminished protective sensation; however, foot and ankle wounds were the most frequent location of wound occurrence regardless of functional neurologic level. The majority of these wounds occurred after episodes of going barefoot or dragging the feet, particularly in a pool. However, there were also two cases of frostbite, four burns (caused by hot bath water or radiators), and two episodes of cellulitis/osteomyelitis in infants who chewed on their feet. Very few foot or ankle wounds could be clearly attributed to malfitting braces. One teenager had lower-extremity spasticity resulting from chronic tethered cord symptoms, which led to a persistent/recurrent clubfoot and breakdown of the lateral side of her foot.

\subsection{Wound setting: Hospital acquired and post-surgical}

Four patients developed pressure ulcers while in a medical setting. Three developed a sacral decubitus ulcer in a medical setting. Two of these ulcers occurred at our institution after prolonged hospitalization following bowel obstruction, and a third occurred in a patient residing in a rehabilitation facility. A fourth patient with midlumbar-level function developed a deep foot ulcer that required below-knee amputation while in a nursing home. He pushed himself about in a wheelchair while barefoot while under care for a pressure ulcer in the opposite limb.

Post-surgical wounds developed in 11/123 patients with wounds. Twenty-one of our clinic patients (5.6\%) underwent spine surgery for scoliosis and/or kyphosis during the review period, and of these nine (43\%) incurred post-operative wound problems either in the immediate post-operative period or associated with their post-operative course. One wound, caused by pressure over the screw of a Vertical Expandable Pros- 


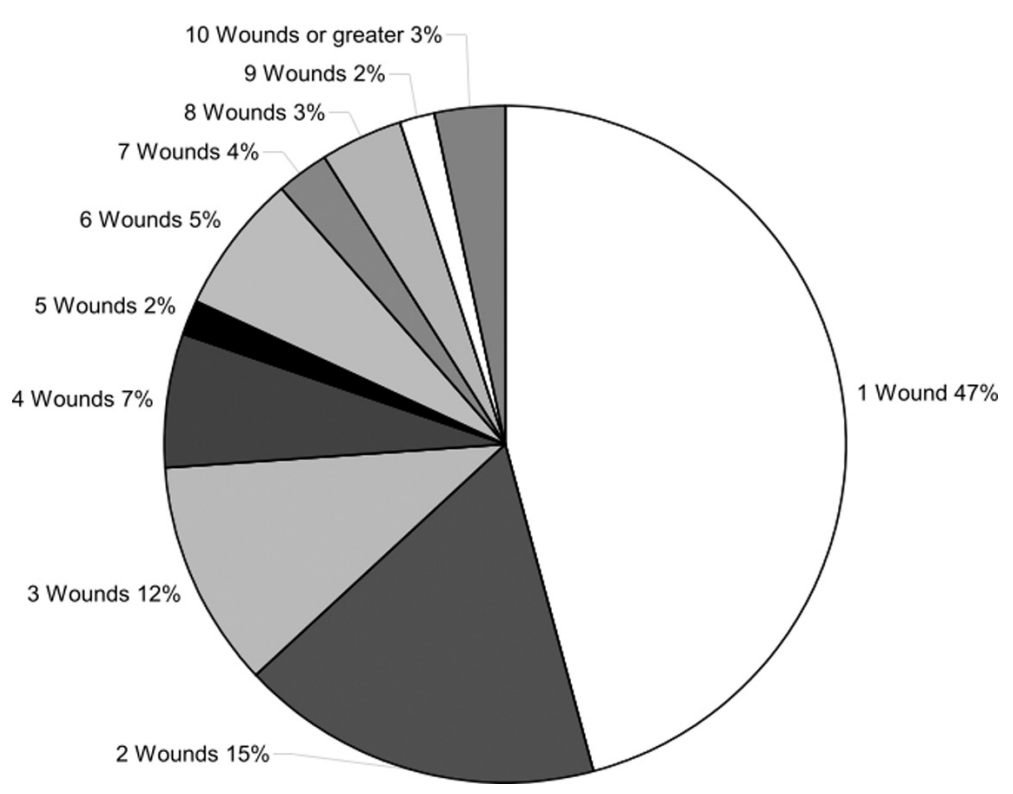

Fig. 4. Fifty-three percent of patients who incurred one wound developed two or more wounds during the observation period.

thetic Titanium Rib (VEPTR) device, developed many years after surgery. Another patient in this group developed a sacral decubitus ulcer while in a rehabilitation facility. The other seven patients with a history of spinal surgery had problems healing their surgical sites in the immediate post-operative period ranging from minor wound-healing problems (three) to major wound breakdown/dehiscence/infection (four). Of the latter, three had thoracic-level function; the fourth, although capable of some high-lumbar neurologic function, also demonstrated evidence of a tethered cord; particularly, marked lower-extremity spasticity and contracture. Only two children developed wounds after lower-extremity surgery. One child developed a surgical-site infection 3 days after tibial and fibular osteotomy and application of external fixator; the other developed pressure ulcers of the forefoot attributed to long-leg casts applied after hip surgery.

\subsection{Chronic wounds}

An important finding was that 20 of 123 (16\%) patients with wounds went on to develop chronic wounds requiring months, if not years, to resolve; seven of the wounds were still actively being treated at the conclusion of our observation period. Sixty percent of patients with chronic wounds were in wheelchairs. Eight wounds were sacral or ischial (five of eight nonambulators), seven were foot wounds (two of seven nonambulators), two were long-standing wounds after spine surgery (two of two nonambulators), two were of the knee or thigh (two of two nonambulators), and one was on the trunk (one of one nonambulator). Four patients required amputation, one removal of all toes, one excision of the patella, and two below-knee. A chronic wound contributed to, but was not responsible for, the demise of the one patient who died during the study period. Thirteen of the 20 patients with chronic wounds were obese, and all 20 had shunts. Our team believed that all 20 had cognitive deficits and/or were regularly noncompliant with suggested skin monitoring.

\subsection{Wound documentation}

Documentation of wound size and stage, as well as of the wound itself (presence of exudate, necrosis, or devitalized tissue, infection, undermining/tunneling, condition of wound edges, color of wound, perfusion to area, and condition of periwound skin), was uncommon in our records until a wound care specialist joined our team in 2006. Similarly, patient/family education regarding wound prevention was rarely documented.

\section{Discussion}

The propensity for wound development in patients with spina bifida is well known [11-19]. However, most studies have only analyzed small subsets of the spina bifida population; for example, many authors 
have focused on patients who require wheelchair mobility, were post-surgical, or presented to an emergency room or hospital. Additionally, since it is only relatively recently that large numbers of patients with spina bifida have been living into adulthood, many studies focus on young patients. At our institution, we have the unique opportunity of caring for a heterogeneous patient population with a wide range of ages (from infancy to 56 years) and functional neurologic levels. Our study advances understanding of wound likelihood and development by more assiduously exploring the anatomical location of wounds in patients with the full spectrum of functional neurologic levels, across a wide age span. In addition, we explored the settings in which wounds are most likely to develop, and include our findings on the incidence of nonhealing wounds.

\subsection{Incidence/risk}

We found that nearly one in three of the patients followed in our Multidisciplinary Spina Bifida Clinic had had at least one wound episode during the 13 year period of observation included in this review. The average age of our patients with wounds was 18.8 years, and wounds were most common in adolescents. This parallels the work of Kinsman et al. [18], who, in their analysis of causes of spina bifida hospital admissions, noted that decubitus ulcers were a comorbidity in $1 \%$ of pediatric admissions and in $8 \%$ of adult admissions. Clearly individuals with spina bifida do not outgrow their risk for developing wounds, and thus, as more of these patients are living longer the need for wound prevention and monitoring is an essential component of wellness education. Interestingly, although infants and young children accounted for a smaller proportion of wounds, they had a wider range of wound etiologies than older patients did. These findings support and expand the findings of other authors and underscore the importance of wound care prevention and education across the lifespan.

Consistent with the findings of Verhoef et al., we found that wounds occurred frequently in patients with the most severe functional neurologic deficits and were more likely to recur in this group as well [17]. In addition, we found that wounds caused by pressure (versus abrasion, burn, etc.) were more common in individuals who used wheelchairs for mobility. Congenital kyphosis, when present, is typically severe, and breakdown most frequently occurred at the point of maximum curvature in individuals with this deformity [25-27].

The majority of wounds, regardless of the patient's functional neurologic level, involved the feet. Like pa- tients with diabetes, our patients were more likely to have wounds of the feet. However, the patients in this study had more ulcers reported on the forefoot, rather than on the heel as has been described in diabetic patients.

Other spina bifida complications (e.g., tethered cord, memory deficits, and obesity) associated with a greater occurrence of pressure ulcers $[11,16]$ were inconsistently documented in our records, however we were able to make a few observations. Most important was the issue of cognitive functioning. Consistent with the general spina bifida population, eighty percent of patients with wounds had a shunt (9); however, all patients with chronic wounds had a shunt. This may be an important area in which patients with spina bifida differ from patients with SCI and diabetes. Research reveals that, on average, individuals with spina bifida score significantly lower than healthy controls on certain neuropsychological tests (including executive functioning) [28-30]. Further, patients with hydrocephalus requiring a shunt score in the lowest range among patients with spina bifida. Thus the presence of a shunt may serve as a warning sign to the wound care team, encouraging investigation as to whether any neuropsychological testing has been done. It is important to carefully assess whether the patient may have limitations that would potentially detract from the ability to manage their wound care. Regardless, the team should be more vigilant in wound monitoring and family education in all spina bifida patients with a shunt, as well as in those for whom executive functioning and problem solving may be more challenging. Future research is needed to develop management strategies that take these deficits into account. As discussed in the Methods section, the data did not allow estimation of obesity rates in our entire population; however, we characterized $65 \%$ of patients with a chronic wounds as obese, which is higher than reported in most spina bifida studies, indicating that patients with obesity also require greater support and supervision by the wound care team.

On a positive note, two-thirds of our patients had no history of a wound. Once a wound developed, however, the patient stood a better than $50 \%$ chance of future wounds. This underscores the need to not just focus on wound care when these patients present, but to also include education about prevention of future injuries immediately.

\subsection{Wound setting: Community}

The majority of our patients with wounds (108/123) developed them in the community, underscoring the 


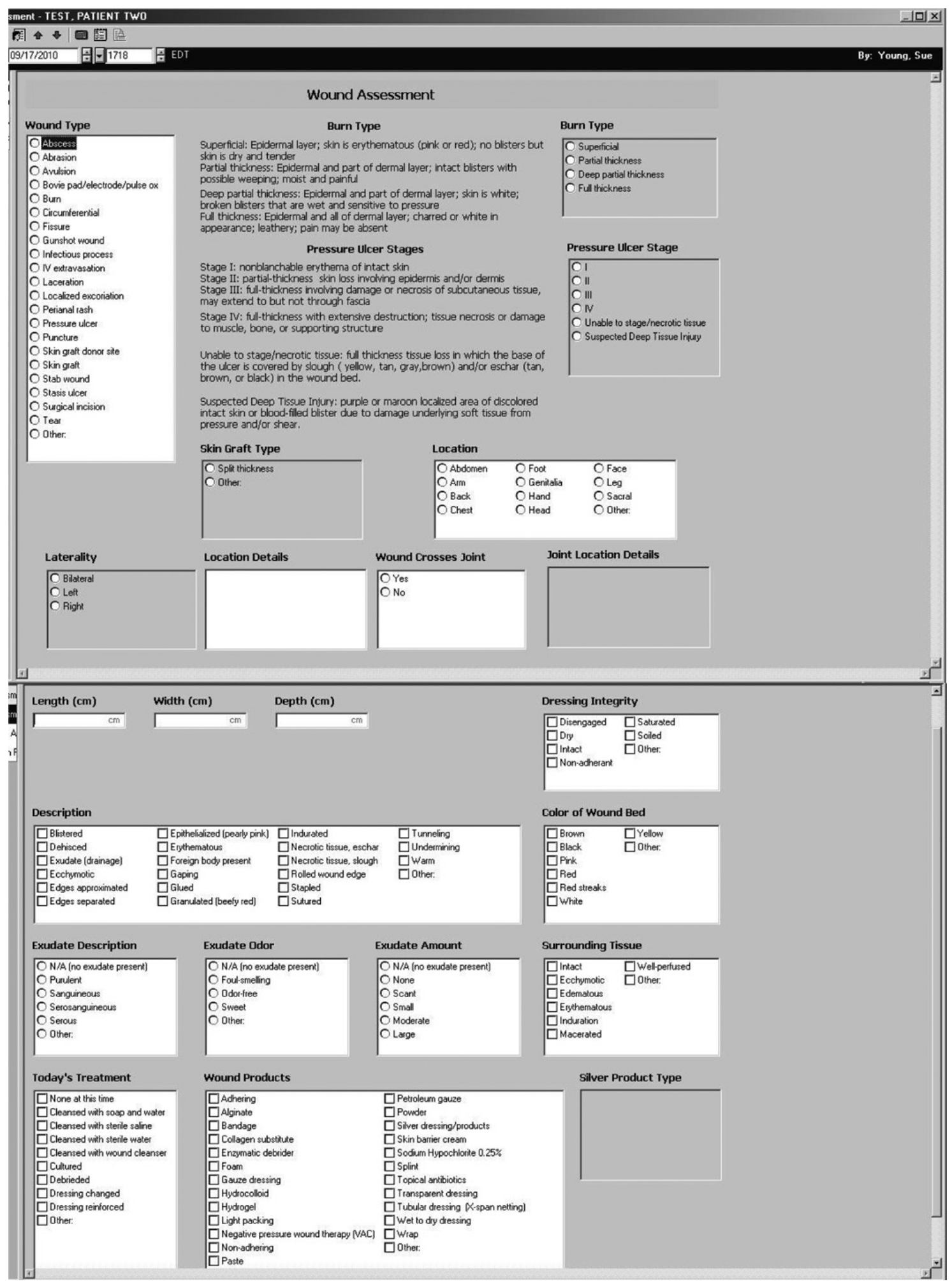

Fig. 5. The PowerForms tool, available in our electronic medical records tool, PowerChart, a product of Cerner ${ }^{\circledR}$ has allowed us to standardize our documentation of wound status and progress. 
need for parent and patient education regarding wound prevention and care. Infants and young children with spina bifida demonstrated a wider range of wound types than older patients did, a phenomenon rarely addressed in the literature. We found no previous reports of infants who developed osteomyelitis as a result of chewing on their feet.

\subsection{Wound setting: Hospital acquired and post-operative}

Although hospital-acquired wounds were very rare (4/375) $(1.1 \%)$ they had the most severe clinical presentation and were usually seen in our sickest patients (those with sepsis and prolonged ICU and hospital stay). Post-operative wounds, although relatively uncommon (11/375 wounds: $3 \%)$, represent an important subset, as several of these wounds required prolonged healing times. Scoliosis and kyphosis are common comorbidities, particularly in patients with thoraciclevel spina bifida. Advances in anesthesia, coupled with improved instrumentation, now make it possible to perform spinal deformity-correction surgery in children with very severe spinal curves. Unfortunately, as demonstrated by numerous authors [31-33], the rate of infection and incision dehiscence is much higher in children with neuromuscular scoliosis than in those with idiopathic scoliosis.

\subsection{Chronic wounds}

We described 20 of the reported wounds as chronic based on severely prolonged healing time. As we discussed in the Methods section, because our recognition of chronic wounds was evolving during the period of this review, we used repeated clinic visits for the same wound and the need for rehabilitation hospital admission for wound care as a way to identify the occurrence of chronic wounds in the early part of this study [2123]. Although we noted considerable problems with healing in several patients, we initially attributed the delay to poor sensation alone. Now, better documentation of wound etiology, patient characteristics, wound characteristics, and failure to improve are alerting our team to diagnose a chronic wound promptly. Research to explain delayed wound healing is moving forward quickly. We seek to take advantage of the extensive scientific research aimed at reducing chronic wounds that has been developed to aid the diabetes and SCI populations, such as specialty mattresses/cushions and antimicrobial dressings, to treat and heal wounds in our spina bifida patients as expeditiously as possible [19, 20,34].

\subsection{Wound documentation, management, prevention, and education}

We have been fortunate to have access to the expertise of a hospital-supported wound care specialist since 2006. She has played a critical role in educating the team about the importance of wound assessment, products, and treatment modalities, as well as in alerting us to risk assessment and prevention strategies for enhancing care. With input from our team, she has developed a wound care documentation form using the PowerForms tool available in our electronic medical records tool, PowerChart, a product of Cerner ${ }^{\circledR}$, which pushes us to rigorously document a detailed wound assessment (Fig. 5). As part of our nutrition assessment, we have added the measurement of arm span [24,25] to our routine clinic intake data in an effort to better define the presence of obesity in our patients. Although we currently focus on issues such as failure to catheterize or weight shift regularly, changing neurologic function, wheelchair use, and poor wheelchair cushioning, we have a growing list of concerns that we are starting to track as possible contributors to wound formation, based on findings from the spina bifida, diabetes, and SCI literature. Particularly, in our growing community of adults, we believe that many of the protective factors essential for avoiding pressure ulcers that have been documented to play a role in patients with SCI (normal weight; return to work and family role; no tobacco, alcohol, or drug abuse; no suicidal behavior; no incarceration) will be essential to track [35]. Assessment of cognitive/executive function and depression are a challenge in a busy multispecialty clinic; however, we strive to include an evaluation of the effect of possible deficits in our wound care management plan [28-30].

Our wound care specialist sees all patients who we deem to be at risk for chronic wounds and reviews their progress with the team weekly. She also provides continuity of care in the inpatient and outpatient arena by working with the patients/families and various team members. Currently, a significant portion of the orthopedics consultation provided at each patient's annual visit to our Multidisciplinary Spina Bifida Clinic focuses on wound prevention. We perform a careful skin survey, as well as a discussion of foot care basics and prevention strategies for wound development. In addition, we urge patients to alert us immediately if any wound problems develop. Given how quickly wound care is evolving, we believe that this level of documentation, treatment, and support will soon become the standard of care and will contribute to improved wound care for patients with spina bifida nationally. 


\subsection{Limitations}

This study has several limitations. First, it was an open-cohort study that retrospectively reviewed inpatient and outpatient hospital records only of children and adults actively followed in the CNMC Multidisciplinary Spina Bifida Clinic in June 2009. By including both adults and children, we may have introduced bias, because adults who choose to be followed in a children's hospital may not be representative of that population as a whole.

Second, due to limitations in our record keeping system, we were able to review patient wound histories over only a 13-year range. Thus, particularly in older patients, it is likely that we missed critical wound events that occurred prior to 1996. Additionally, we missed any events that were not cared for in our clinic.

Third, historically our clinic has not collected information that might have shed more light on risk factors for wounds, particularly cognitive status/executive functioning and BMI. Although educational testing was likely performed in many of the patients' schools, reports were not routinely kept in the medical files. Thus, although the authors feel that problems with wound healing are, at least in part, impacted by problems with executive functioning, we cannot document that concept with our existing data. As described in our methods section, height was measured only in patients capable of standing, so BMI could not be calculated in many cases, so we had to rely on the authors' consensus. Similarly, because chronic wounds were not a part of our wound care vocabulary early in the review period, we used repeated clinic visits for the same wound and/or the need for rehabilitation hospital admission for wound care as surrogates for identifying chronic wounds in some cases from the early part of our collection period. In addition, several authors have underscored the fact that many individuals with spina bifida lose function over time, typically due to having a tethered cord [9]. Unfortunately, in most cases, our team did not feel that the historical record allowed us to comment on the role that a tethered cord might have played in wound development.

Finally, our clinic serves a multi-state area, and many patients received their definitive care from home care and physician services in the communities where they resided, thus limiting the documentation of wound management in our hospital records.

In conclusion, the increased longevity of patients with spina bifida highlights the importance of taking proactive steps to avoid wound development, es- pecially among adolescents. Our open-cohort study demonstrates that a substantial fraction of these patients are likely to develop wounds under current educational and care regimens. In the population studied, the vast majority of these wounds developed in the community, particularly among wheelchair users, and wounds on the feet were more common than in other areas. Moreover, a first wound was shown to be a strong predictor of a future wound, and chronic wounds present a therapeutic challenge. Such basic parameters suggest how parent and patient education might usefully be focused, and how proactive intervention to preclude wounds might be constructed. While our team at CNMC benefits from having a wound care specialist, it is clear from our data that wound education and vigilance are ultimately the responsibility of the orthopedist in partnership with the spina bifida care team, who must integrate the various risk factors. To the extent that we are able to prevent wounds, we will reduce the significant burdens they place on the health care system, and enhance the patients' well-being, school attendance, and participation in the working life of society at large.

\section{Conflict of interest}

The authors report no conflict of interest.

\section{References}

[1] Centers for Disease Control and Prevention. Spina bifida and anencephaly before and after folic acid mandate - United States, 1995-1996 and 1999-2000. Morb Mortal Wkly Rep. 2004 May; 53(17); 362-5.

[2] National Birth Defects Prevention Network. January 2009 statistics. Available from: www.nbdpn.org/current/resources/ profiles.html. Accessed December 27, 2011.

[3] Williams LJ, Rasmussen SA, Alina Flores A, Kirby RS, Edmonds LE. Decline in the prevalence of spina bifida and anencephaly by race/ethnicity: 1995-2002. Pediatrics. 2005; 116 : 580-6.

[4] Boockvar JA, Loudon W, Sutton LN. Development of the Spitz-Holter valve in Philadelphia. J Neurosurg. 2001; 95: 145-7.

[5] Oktem IS, Menkü A, Ozdemir A. When should ventriculoperitoneal shunt placement be performed in cases with myelomeningocele and hydrocephalus? Turk Neurosurg. 2008; 18: 387-91.

[6] Davis BE, Daley CM, Shurtleff DB et al. Long-term survival of individuals with myelomeningocele. Pediatr Neurosurg. 2005 Jul-Aug; 41(4): 186-91.

[7] Bol KA, Collins JS, Kirby RS, National Birth Defects Prevention Network. Survival of infants with neural tube defects in the presence of folic acid fortification. Pediatrics. 2006; Mar; 117(3): 803-13. 
[8] Wong LY, Paulozzi LJ. Survival of infants with spina bifida: A population study, 1979-94. Paediatri Perinat Epidemiol. 2001; Oct; 15(4): 374-8.

[9] Bowman RM, McLone DG, Grant JA, Tomita T, Ito JA. Spina bifida outcome: A 25-year prospective. Pediatr Neurosurg. 2001; Mar; 34(3): 114-20.

[10] Oakeshott P, Hunt GM, Poulton A, Reid F. Expectation of life and unexpected death in open spina bifida: a 40-year complete, non-selective, longitudinal cohort study. Dev Med Child Neurol. 2010 Aug; 52(8): 749-53. Epub 2009 Dec 9.

[11] Caterino JM, Scheatzle MD, D'Antonio JA. Descriptive analysis of 258 emergency department visits by spina bifida patients. J Emerg Med. 2006; 31: 17-22.

[12] Dicianno BE, Kurowski BG, Yang JM, Chancellor MB, Bejjani GK, Fairman AD, Lewis N, Sotirake J. Rehabilitation and medical management of the adult with spina bifida. Am J Phys Med Rehabil. 2008; 87: 1027-50.

[13] Mazur JM, Shurtleff D, Menelaus M, Colliver J. Orthopedic management of high-level spina bifida. Early walking compared with early use of a wheelchair. J Bone Joint Surg Am. 1989; 71: 56-61.

[14] Murphy KM. Managing skin health in obese children with spina bifida: an overview and case study. Ostomy Wound Manage. 2008; 54: 34-43.

[15] Okamoto GA, Lamers JV, Shurtleff DB. Skin breakdown in patients with myelomeningocele. Arch Phys Med Rehabil. 1983; 64: 20-3

[16] Plaum PE, Riemer G, Frøslie KF, Rand-Hendriksen S. Pressure sores in adult spina bifida (SB) patients - a questionnaire based interview of the Norwegian population. Cerebrospinal Fluid Research. 2006; 3: 14.

[17] Verhoef M, Barf HA, Post MW, van Asbeck FW, Gooskens $\mathrm{RH}$, Prevo AJ. Secondary impairments in young adults with spina bifida. Dev Med Child Neurol. 2004; 46: 420-7.

[18] Kinsman SL, Doehring MC. The cost of preventable conditions in adults with spina bifida. Eur J Pediatr Surg. 1996; 6(Suppl 1): 17-20.

[19] Dorresteijn JA, Kriegsman DM, Valk GD. Complex interventions for preventing diabetic foot ulceration. Cochrane Database Syst Rev. 2010; 1: CD007610.

[20] Wu SS, Ahn C, Emmons KR, Salcido RS. Pressure ulcers in pediatric patients with spinal cord injury: A review of assessment, prevention, and topical management. Adv Skin Wound Care. 2009; 22: 273-84; quiz 285-286.

[21] Wolcott RD, Rhoads DD, Bennett ME, Wolcott BM, Gogokhia L, Costerton JW, Dowd SE. Chronic wounds and the medical biofilm paradigm. J Wound Care. 2010; 19: 45$46,48-50,52-3$.
[22] Ammons CB. Anti-biofilm strategies and the need for innovations in wound care. Recent Pat Antiinfect Drug Discov. 2010; 5: 10-7.

[23] Gélis A, Dupeyron A, Legros P, Benaïm C, Pelissier J, Fattal C. Pressure ulcer risk factors in persons with spinal cord injury part 2: The chronic stage. Spinal Cord. 2009; 47: 651-61.

[24] Dosa NP, Foley JT, Eckrich M, Woodall-Ruff D, Liptak GS. Obesity across the lifespan among persons with spina bifida. Disabil Rehabil. 2009; 31(11): 914-20.

[25] Rotenstein D, Adams M, Reigel DH. Adult stature and anthropomorphic measurements of patients with myelomeningocele. Eur J Pediatr. 1995 May; 154(5): 398-402. 26. Niall DM,

[26] Dowling FE, Fogarty EE, Moore DP, Goldberg C. Kyphectomy in children with myelomeningocele: A long-term outcome study. J Pediatr Orthop. 2004; 24: 37-44.

[27] Kocaoğlu B, Erol B, Akgülle H, Gasimov E, Yalçin S. Combination of Luque instrumentation with polyaxial screws in the treatment of myelomeningocele kyphosis. J Spinal Disord Tech. 2008; 21; 199-204.

[28] Hampton LE, Fletcher JM, Cirino PT, Blaser S, Kramer LA, Drake J, Dennis M. Hydrocephalus status in spina bifida: an evaluation of variations in neuropsychological outcomes. J Neurosurg Pediatr. 2011 Sep; 8(3): 289-98.

[29] Bellin MH, Zabel TA, Dicianno BE, Levey E, Garver K, Linroth $\mathrm{R}$, Braun P. Correlates of depressive and anxiety symptoms in young adults with spina bifida. J Pediatr Psychol. 2010 Aug; 35(7):778-89. Epub 2009 Oct 30.

[30] Dennis M, Barnes MA.The cognitive phenotype of spina bifida meningomyelocele. Dev Disabil Res Rev. 2010; 16(1): 31-9.

[31] Ko AL, Song K, Ellenbogen RG, Avellino AM. Retrospective review of multilevel spinal fusion combined with spinal cord transection for treatment of kyphoscoliosis in pediatric myelomeningocele patients. Spine. 2007; 32: 2493-501.

[32] Szöke G, Lipton G, Miller F, Dabney K. Wound infection after spinal fusion in children with cerebral palsy. J Pediatr Orthop. 1998; 18: 727-33.

[33] Tredwell SJ, Reilly CW. Complications of spinal surgery. In: Weinstein SL, ed. Pediatric Spine Surgery. $2^{\text {nd }}$ ed. Philadelphia: Lippincott, Williams and Wilkins; 2001: 561-82.

[34] Horn PL, Ruth B, Kean JR. Use of wound VAC therapy in pediatric patients with infected spinal wounds. Orthop Nurs. 2007; 26: 317-22.

[35] Krause JS, Vines CL, Farley TL, Sniezek J, Coker J. An exploratory study of pressure ulcers after spinal cord relationship to protective behaviors and risk factors. Arch Phys Med Rehabil. 2001; 82: 107-13. 